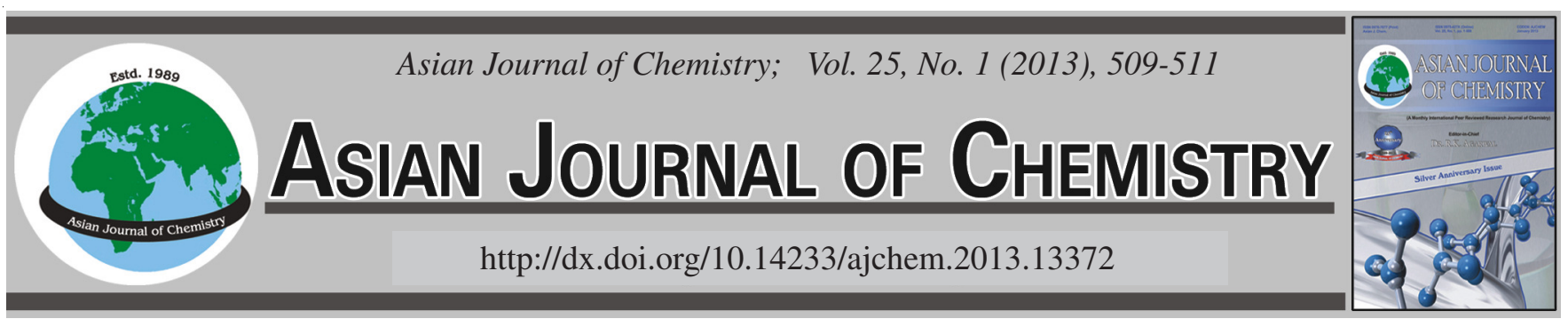

\title{
Preparation of 2(3H)-Benzimidazolone and its Derivative Under Aqueous Condition As a Potential Agent for Antidiabetic Compounds
}

\author{
Muhammad Azhar Abbas ${ }^{1,2, *}$, Shahid Hameed ${ }^{1, *}$ and Joerg Kressler ${ }^{2}$
}

${ }^{1}$ Department of Chemistry, Quaid-i-Azam University, Islamabad-45320, Pakistan

${ }^{2}$ Department of Chemistry, Institute of Physical Chemistry, Martin Luther University, 06120 Halle (Saale), Germany

*Corresponding authors: Fax: +92 51 90642241; Tel: +92 301 5565080,5190642133; E-mail: prof_chem27@yahoo.com; shameed@qau.edu.pk

\begin{abstract}
A focused library of $2(3 H)$-benzimidazolone and its derivatives has been synthesized in an attempt to identify their antidiabetic potential. All the products have been synthesized under aqueous conditions in lesser time with better yield and purity. A new effective and convenient method for in situ synthesis of five member heterocyclic ring by reaction of phenylene diamine with urea in solvent phase. All the synthesized compounds were characterized by modern spectroscopic techniques.
\end{abstract}

Key Words: Benzimidazolone, Cyclic urea, Antidiabetic potential, Phenylene diamine, Heteocyclic ring.

\section{INTRODUCTION}

There is an emergent interest over the last many years for the synthesis of benzimidazole-based heterocycles due to its importance in functioning of biologically important molecules in displaying wide range of biological properties ${ }^{1,2}$. Benzimidazolonic scaffolds and their related cyclic urea derivatives are important heterocyclic building blocks for the species involved in inhibition of aldose reductase, antagonism of neurotransmitter receptors, antiulcer activity ${ }^{3}$, antimicrobial activity and modulation of ion channels ${ }^{4}$. Such spectrum of biological activity has attracted considerable attention for these compounds. The synthesis of these heterocyclic compounds having privileged structures has been reported in literature by different methods of synthesis, solid phase synthesis, from phosgene gas $^{5}$ and from anthranilic acid azides ${ }^{6}$. After the comprehensive survey, it has been observed that the methods, which are still used are not simple and also give low yield with complex work up of the reaction mixture. The methods that enable the simple and rapid production of these compounds are very useful for the identification of new lead structures and have importance in pharmaceutical industry. Although some advancement in synthetic methods were achieved, but there is no improvement in yields. To improve the yield and simplify the reaction procedure, alternative method is schemed for the preparation of these pharmacological active compounds.

Among the five and six membered nitrogenous heterocyclic compounds the greatest enzyme-inducing activity is found and such properties are observed in these compounds demonstrating a wide variety of biochemical and pharmacological properties ${ }^{7}$.

There are several synthetic routes to $2(3 H)$-benzimidazolones $^{8}$ which involve $o$-phenylenediamine as the starting material. In literature it is found that bezimidazolone was synthesized by different methods as shown in Scheme-I, but there is no convenient way to achieve better yield by easy workup. These compounds are versatile key intermediates in the synthesis of our target antidiabetic compounds.

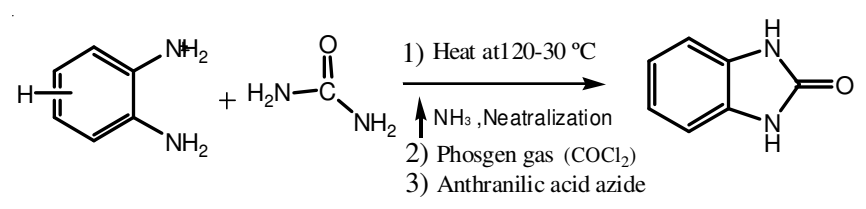

Scheme-I: Methods of benzimidazolone preparation (reported in literature)

The structure of the target compound and intermediates were confirmed by using the ${ }^{1} \mathrm{H}$ and ${ }^{13} \mathrm{C}$ NMR, FT-IR, MS and elemental analysis (CHNS) techniques.

\section{EXPERIMENTAL}

Melting points of the compounds were determined using Gallenkemp melting point apparatus. FT-IR spectra were recorded on a Hitachi model 270-50 spectrophotometer either as $\mathrm{KBr}$ discs or as neat liquids; ${ }^{1} \mathrm{H}$ NMR spectra were recorded on a Bruker Avance $300 \mathrm{MHz}$ NMR spectrophotometer in $\mathrm{CDCl}_{3}$ solutions using TMS as an internal standard; and EIMS 
on a MAT-112-S machine at $70 \mathrm{eV}$. All the reactions were monitored by TLC using Pre-coated Kieselgel- $60 \mathrm{HF}_{254}$ TLC plates.

Synthesis of 2(3H)-benzimidazolone: 1,2 Phenylene diamine $(0.05 \mathrm{~mol})$ and urea $(0.015 \mathrm{~mol})$ were placed in a 100 $\mathrm{mL}$ round bottom flask, dissolved in $25 \% \mathrm{THF} /$ water solution and stir vigorously, then added 1-2 drops of acetic acid as a catalyst. The reaction mixture was refluxed on oil bath at 100 $120{ }^{\circ} \mathrm{C}$ for $4.5 \mathrm{~h}$ and then for $0.5 \mathrm{~h}$ at $135^{\circ} \mathrm{C}$ to remove the remaining ammonia gas. Completion of the reaction was continuously checked by TLC. After completion of the reaction, the mixture was stayed for a long time near $5 \mathrm{~h}$ at room temperature. The resulting precipitates were filtered and washed with ethanol thrice and then recrystallized in methanol. The precipitates were filtered, dried (anhydrous $\mathrm{MgSO}_{4}$ ) for overnight. The product obtained was pale yellow in colour with good yield and sharp m.p. Elemental analysis: $\mathrm{C}_{7} \mathrm{H}_{6} \mathrm{~N}_{2} \mathrm{O}$ (134): calcd. C 62.68, H 4.51, N 20.89; found C 62.70, H 4.53, N 20.91 .

Synthesis of 5-nitro-2(3H)-benzimidazolone: 5-Nitro1,2-phenylene diamine $(0.05 \mathrm{~mol})$ and urea $(0.015 \mathrm{~mol})$ were placed in a $100 \mathrm{~mL}$ round bottom flask, dissolved in $25 \%$ $\mathrm{THF} /$ water solution and stir vigorously, then added 1-2 drops of acetic acid as a catalyst. The reaction mixture was refluxed on oil bath at $100-120^{\circ} \mathrm{C}$ for $4.5 \mathrm{~h}$ and then for $0.5 \mathrm{~h}$ at $135^{\circ} \mathrm{C}$ to remove the remaining ammonia gas. Completion of the reaction was continuously checked by TLC. After completion of the reaction, the mixture was stayed for a long time near $5 \mathrm{~h}$ at room temperature. The resulting precipitates were filtered and washed with ethanol 3 times and then recrystallized in methanol. The precipitates were filtered, dried (anhydrous $\mathrm{MgSO}_{4}$ ) for overnight. The product was yellowish brown in colour. Elemental analysis: $\mathrm{C}_{7} \mathrm{H}_{5} \mathrm{~N}_{3} \mathrm{O}_{3}$ (179.13): calcd. C 46.92, H 2.81, N 23.46 ; found C 46.88, H 2.86, N 23.54.

\section{RESULTS AND DISCUSSION}

2-(3H)-Benzimidazolone and its derivative 5-nitro-2(3H)benzimidazolone were synthesized in liquid phase of THF/ water by the reaction of $o$-phenylene diamine with urea in the presence of acetic acid as a catalyst as shown in Scheme-II. The contrasting results were obtained by this attempt as compared to reported methods. A number of such compounds with different substitution patterns have been synthesized ${ }^{9,10}$ to check their medicinal properties.

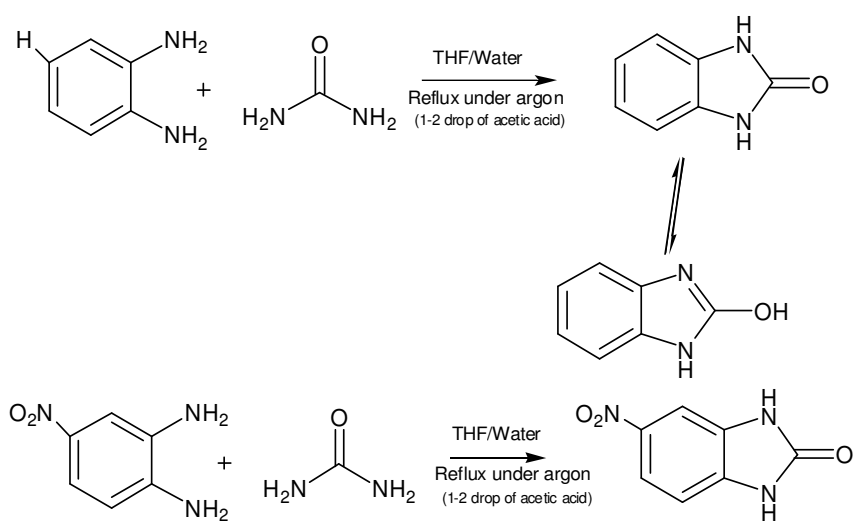

Scheme-II: Synthesis of 2(3H)-benzimidazolone and 5-nitro-2(3H)-benzimidazolone
If comparison is made between the synthetic route available in literature and new proposed method, very encouraging results are achieved and it is found to be a very facile method for preparation of biological active bezimidazolone and its derivative.

The methods found in literature to obtain benzimidazolone by the reaction of phosgene with $o$-phenylenediamine has some disadvantages due to formation of hydrochloric acid, which requires special safety arrangements due to its toxic nature. Similarly the method with urea in solid phase reaction has also some disadvantages, like the use of high temperature, continuous removal of ammonia gas and difficulty in stirring the reaction mixture.

Discrepancies have been eliminated in our proposed new and convenient method for the preparation of benzimidazolone with better yield. The products obtained in result of this most promising synthetic approach are in good yield (Table-1).

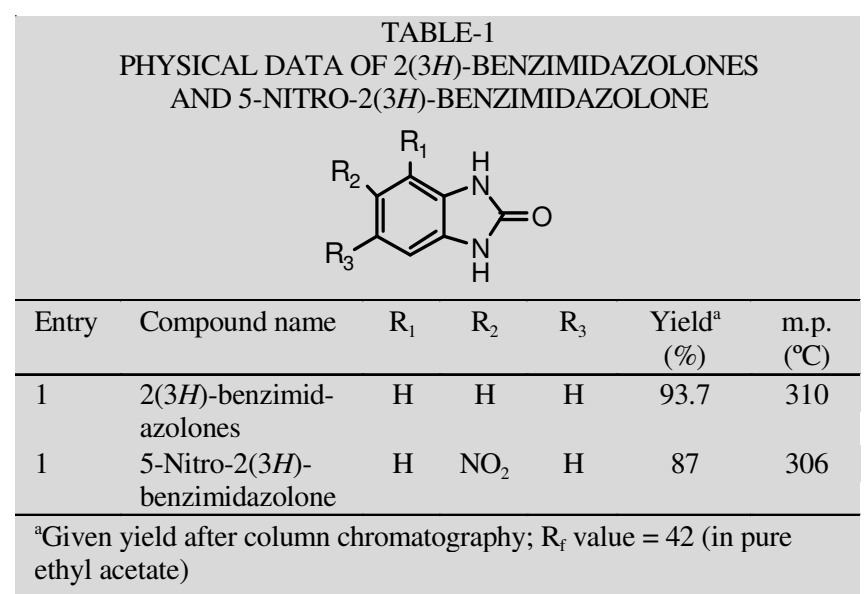

The structures of all the synthesized compounds were established by modern spectroscopic techniques and purity ascertained by elemental analysis which supports the idea of this work. The reaction Scheme-II elaborates the synthesis method.

The FT-IR spectra showed a bond at $1740 \mathrm{~cm}^{-1}$ and 1110 $\mathrm{cm}^{-1}$ for $-\mathrm{NCO}$ stretching and $\mathrm{C}-\mathrm{H}$ aromatic vibration as shown in Table-2. On the other hand when $\mathrm{H}$ is replaced by $\mathrm{NO}_{2}$ group at positon No. 5 of benzene ring then it is observed an Ar- $\mathrm{NO}_{2}$ asymmetric stretching at $1520 \mathrm{~cm}^{-1}$ which give the clear indication of introduction of $-\mathrm{NO}_{2}$ group as shown in Table-3.

In ${ }^{1} \mathrm{H}-\mathrm{NMR}$ spectra of $2(3 \mathrm{H})$-benzimidazolone, signals for $\mathrm{NH}$ protons were observed in a downfield region in the range of $10.59 \mathrm{ppm}$. The protons $\mathrm{H}$ 4, 5, 6, 7 are appeared at

\begin{tabular}{llc}
\multicolumn{3}{c}{ TABLE-2 } \\
FT-IR SPECTRAL DATA OF \\
2(3H)-BENZIMIDAZOLONES WHEN R=H \\
\hline 1 & Functional group behaviour & $\mathrm{v}\left(\mathrm{cm}^{-1}\right)$ \\
\hline 2 & -NCO stretching & 1740 \\
3 & C-H aromatic vib & 1110 \\
4 & C-H vib deformation & $830-880$ \\
5 & C=C aromatic vib & $1385-1395$ \\
6 & -C-H aromatic stretching & $3182-3190$ \\
7 & -NH free group & $3250-3400$ \\
\hline
\end{tabular}




\begin{tabular}{lll}
\hline \multicolumn{2}{c}{ TABLE-3 } \\
FT-IR SPECTRAL DATA OF \\
& $2(3 H)$-BENZIMIDAZOLONES WHEN R=NO \\
\hline Entry & Functional group behaviour & $\mathrm{v}\left(\mathrm{cm}^{-1}\right)$ \\
\hline 1 & $-\mathrm{NCO}$ stretching & 1745 \\
2 & $\mathrm{Ar}-\mathrm{NO}_{2}$ & $1525-1520$ \\
2 & $\mathrm{C}-\mathrm{H}$ aromatic vib & 1110 \\
3 & $\mathrm{C}-\mathrm{H}$ vib deformation & $880-830$ \\
4 & $\mathrm{C}=\mathrm{C}$ aromatic vib & $1395-1385$ \\
5 & $=\mathrm{C}-\mathrm{H}$ aromatic stretching & $3190-3182$ \\
6 & -NH free group & $3400-3250$ \\
7 & $\mathrm{C}=\mathrm{O}$ overtone & $3400-3350$ \\
\hline
\end{tabular}

$6.91 \mathrm{ppm}$. In ${ }^{13} \mathrm{C}$ NMR the signal in the range of $155.72 \mathrm{ppm}$ was assigned to the carbonyl carbon. Carbon 4,5,6,7 appeared in the rang of 119-123 ppm (Fig. 1).

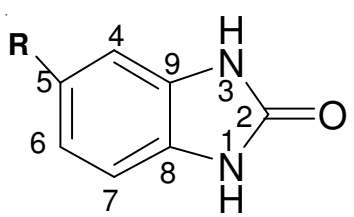

Fig. 1. Representation of benzimidazolone structure with carbon numbering

${ }^{1} \mathrm{H}$ NMR of 2(3H)-benzimidazolone and 5-nitro-2(3H)benzimidazolone are shown in Tables 4 and 5 showed that the protons of $\mathrm{H}-1$ and $\mathrm{H}-3$ resonated in the region of $10.7 \mathrm{ppm}$ and $11.40 \mathrm{ppm}$ as singlet. The $\mathrm{H}-5$ of $2(3 \mathrm{H})$-benzimidazolone was replaced by $\mathrm{NO}_{2}$ group and it may change the chemical shift pattern of neighboring protons.

\begin{tabular}{|c|c|c|c|c|c|}
\hline \multicolumn{6}{|c|}{ 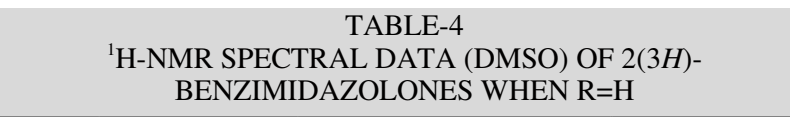 } \\
\hline Entry & \multicolumn{2}{|c|}{ No. of proton } & \multicolumn{2}{|c|}{ Chemical shift $\delta(\mathrm{ppm})$} & Multiplicity \\
\hline 1 & \multicolumn{2}{|c|}{$\mathrm{H}-1,3$} & \multirow{2}{*}{\multicolumn{2}{|c|}{$\begin{array}{l}10.7 \\
6.90 \\
\end{array}$}} & $2 \mathrm{H}, \mathrm{s}$ \\
\hline 2 & \multicolumn{2}{|c|}{$\mathrm{H}-4,5,6,7$} & & & $4 \mathrm{H}, \mathrm{s}$ \\
\hline \multicolumn{6}{|c|}{ 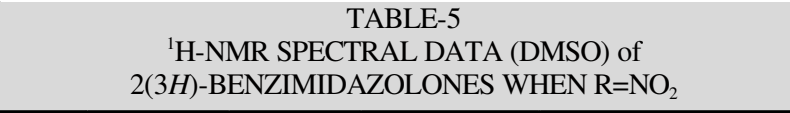 } \\
\hline Entry & $\begin{array}{l}\text { No. of } \\
\text { proton }\end{array}$ & $\delta(\mathrm{ppm})$ & Multiplicity & $\begin{array}{l}\text { Cou } \\
\text { (J H }\end{array}$ & ing constant \\
\hline 1 & $\mathrm{H}-1,3$ & 11.40 & $2 \mathrm{H}, \mathrm{s}$ & - & \\
\hline 2 & $\mathrm{H}-4$ & 8.26 & $1 \mathrm{H}, \mathrm{dd}$ & $\mathrm{J}_{4 \cdot 6}$ & .05 (meta) \\
\hline 3 & H-6 & 7.87 & $1 \mathrm{H}, \mathrm{d}$ & & $\begin{array}{l}.75 \text { (ortho) } \\
.01 \quad \text { (meta) }\end{array}$ \\
\hline 4 & H-7 & 7.68 & $1 \mathrm{H}, \mathrm{d}$ & $J_{7-6}$ & .53 (ortho) \\
\hline
\end{tabular}

The ${ }^{13} \mathrm{C}$ NMR spectra of both the compounds showed that carbonyl carbon of heterocyclic ring appeared at $156 \mathrm{ppm}$ and change in shift of C-5 is observed in case of 5-nitro-2(3H)benzimidazolone from $121 \mathrm{ppm}$ to $142 \mathrm{ppm}$ listed in Tables 6 and 7 , which indicate the shift towards down field region due to presence of electron with drawing $-\mathrm{NO}_{2}$ group.

In ${ }^{1} \mathrm{H}$ NMR spectra of 5-nitro-2 $(3 \mathrm{H})$-benzimidazolone. It is also observed the signal of $\mathrm{H} 4,6,7$ appeared at different chemical shifts due to presence of $-\mathrm{NO}_{2}$ group at 5-position in their neighbor. Thus, the proton $\mathrm{H}-4$ resonated at $8.26 \mathrm{ppm}$ as doublet with coupling constant of $2.03 \mathrm{~Hz}$ and H-6 resonated at $7.87 \mathrm{ppm}$ as a doublet of doublet with ortho coupling constant of $8.75 \mathrm{~Hz}$ and meta coupling constant of $2.01 \mathrm{~Hz}$. The other proton $\mathrm{H}-7$ resonated at $7.68 \mathrm{ppm}$ as a doublet with coupling constant $8.53 \mathrm{~Hz}$.

\begin{tabular}{ccc}
\multicolumn{3}{c}{ TABLE-6 } \\
& $\begin{array}{c}{ }^{13} \text { C NMR SPECTRAL DATA (DMSO) of } 2(3 H)- \\
\text { BENZIMIDAZOLONES WHEN R=H }\end{array}$ \\
\hline Entry & No. of ${ }^{13} \mathrm{C}$ & Chemical shift $\delta(\mathrm{ppm})$ \\
\hline 1 & $\mathrm{C} 4,7$ & 109 \\
2 & $\mathrm{C} 5,6$ & 121 \\
3 & $\mathrm{C} 8,9$ & 130 \\
4 & $\mathrm{C} 2$ & 156 \\
\hline
\end{tabular}

\begin{tabular}{|c|c|c|}
\hline \multicolumn{3}{|c|}{$\begin{array}{c}\text { TABLE-7 } \\
{ }^{13} \mathrm{C} \text {-NMR SPECTRAL DATA (DMSO) OF } 2(3 H) \text { - } \\
\text { BENZIMIDAZOLONES WHEN R=NO }{ }_{2}\end{array}$} \\
\hline Entry & No. of ${ }^{13} \mathrm{C}$ & Chemical shift $\delta(\mathrm{ppm})$ \\
\hline 1 & $\mathrm{C} 2$ & 155.91 \\
\hline 2 & $\mathrm{C} 4$ & 105.00 \\
\hline 3 & $\mathrm{C} 5$ & 141.70 \\
\hline 4 & C6 & 109.00 \\
\hline 5 & C7 & 119.00 \\
\hline
\end{tabular}

In ${ }^{13} \mathrm{C}$ NMR the signal in the range of $155.91 \mathrm{ppm}$ was assigned to the carbonyl carbon and for carbon No. 5 of $\mathrm{C}-\mathrm{NO}_{2}$ group of aromatic ring was at $141.70 \mathrm{ppm}$. In the compound 5-nitro-2 $(3 H)$-benzimidazolone due to the presence of $-\mathrm{NO}_{2}$ group at 5-position the chemical environment of $\mathrm{C} 4$, 6,7 was changed. Thus C-4 resonated at $105, \mathrm{C}-6$ at $109 \mathrm{ppm}$ and $\mathrm{C}-7$ at $119 \mathrm{ppm}$.

\section{ACKNOWLEDGEMENTS}

The authors thank and grateful to Higher Education Commission of Pakistan for their financial support regarding this work under indigenous scholarship scheme and especially to Prof. Dr. Joerg Kressler (Institute für Chemie, Martin-Luther University Halle-Wittenberg, Halle (Saale), Germany for technical support.

\section{REFERENCES}

1. E. Nicolai, J. Goyard, T. Benchetrit, M. Jean, F. Caussade, A. Virone, Delchambre and A. Chantal, J. Med. Chem., 36, 1175 (1993).

2. R.B. Silverman, The Organic Chemistry of Drug Design and Drug Action, Elsevier Academic Press: Oxford, edn. 2 (2004).

3. X.n-J. Xu and Y.-X. Zong, Tetrahedron Lett., 48, 129 (2007).

4. M.C. McKay, S.I. Dworetzky, N.A. Meanwell, S.-P. Olesen, P.H. Reinhart, I.B. Levitan, J.P. Adelman and V.K. Gribkoff, J. Neurophysiol., 71, 873 (1994)

5. German Patent No. $2,905,876$

6. R.K. Smalley and T.E. Bingham, J. Chem. Soc. C, 2481 (1969).

7. D.W. Wooley, J. Biol. Chem., 152, 225 (1944).

8. O. Prakash, H. Batra, H. Kaur, P.K. Sharma, V. Sharma, S.P. Singh and R.M. Moriatry, Synthesis, 541 (2001).

9. D.M. Smith and P.M. Preston, Chem. Heterocycl. Comp., 40, 331 (1981).

10. M.R. Grimmett, A.R. Katritzky, C.W. Rees and K.T. Potts, Comprehensive Heterocyclic Chemistry, Pergamon Press, Oxford, Ch. 33, p. 2101 (1990). 